\title{
The Effect of the Hemofiltration-Body Surface Area on the Mortality and Morbidity during Cardiopulmonary Bypass
}

\author{
Kadir Burhan Karadem1, Burcin Abud2, Ayse Gül Kunt ${ }^{2}$ \\ ${ }^{1}$ Cardiovascular Surgery Department, Isparta City Hospital, Isparta, Turkey \\ ${ }^{2}$ Cardiovascular Surgery Department, Izmir Tepecik Research and Education Hospital, Izmir, Turkey \\ Email: *burcinabud@hotmail.com
}

How to cite this paper: Karadem, K.B., Abud, B. and Kunt, A.G. (2018) The Effect of the Hemofiltration-Body Surface Area on the Mortality and Morbidity during Cardiopulmonary Bypass. World Journal of Cardiovascular Surgery, 8, 140-149. https://doi.org/10.4236/wjcs.2018.88013

Received: July 6, 2018

Accepted: August 7, 2018

Published: August 10, 2018

Copyright $\odot 2018$ by authors and Scientific Research Publishing Inc. This work is licensed under the Creative Commons Attribution International License (CC BY 4.0).

http://creativecommons.org/licenses/by/4.0/

\begin{abstract}
The aim of this study is to investigate the effect of the hemofiltration-body surface area on mortality and morbidity during cardiopulmonary bypass (CBP). A total of 226 patients were divided into two groups as hemofiltration (HF) performed or not performed. The patients to whom hemofiltration was performed were also divided into three subgroups after the distribution analysis which was done according to body surface area. All patients were compared according to the relationship of hemofiltration-body surface area during cardiopulmonary bypass in the interms of mortality and morbidity. There was no statistically significant relationship between the subgroups according to the amount of hemofiltration by square meters $(\mathrm{p}=0.818)$. There was statistically significant difference in total perfusion times and total hospital stay $(\mathrm{p}=0.025 ; \mathrm{p}=0.038)$ between the subgroups which were divided by the amount of hemofiltration in square meters. As a result, no effect was observed on the mortality of the relationship between the amount of hemofiltration applied during CBP and body surface area.
\end{abstract}

\section{Keywords}

Hemofiltration, Body Surface Area, Cardiopulmonary Bypass

\section{Introduction}

After widespread use of cardiopulmonary by-pass (CBP) in the mid-seventies, hemofiltration (HF) has become a frequently used procedure in open heart surgery. It is aimed to obtain beneficial effects of hemodilution during CBP. However, hemodilution decreases intravascular osmotic pressure and causes intersti- 
tial edema [1]. There is also an increase in total body fluid mass due to CPB. This excess fluid prevents normal functioning of the organs and tissues by leaking into the space between tissues [2]. Increase in the amount of total body fluid has negative effects on mortality and morbidity in the perioperative period [3]. The purpose of using hemofiltration is to reduce the volumetric load of the patient and to provide hemoconcentration in this regard. Thus, it is aimed to reduce the amount of blood and blood products transfused to the patient. According to some studies, hemofiltration applied during CPB had more significantly beneficial effects on cardiac, pulmonary, hepatic, renal, hematological and immunological functions in the postoperative period than in the groups without hemofiltration [4] [5] [6] [7]. There is no clear indication for the amount of hemofiltration applied during cardiopulmonary bypass when the current literature is searched. Patient's volume balance and intraoperative hematocrit values are determined according to the amount remaining in the venous reservoir volume. Exactly from here, the question "Is there any effective value for the hemofiltration applied to the patients" becomes a current issue.

Our purpose in this study is to study the effects of the relationship between the amount of hemofiltration applied during cardiopulmonary bypass and body surface area, on mortality and morbidity.

\section{Material and Methods}

In this study, the patients who underwent coronary artery bypass surgery between June 2009 and June 2013 at Izmir Tepecik Research and Education Hospital, were retrospectively analyzed. The other open heart surgery patients out of coronary arterial bypass grafting and the patients with missing data were excluded from the study. A total of 226 patients were divided into two groups as hemofiltration performed or not performed. The patients to whom hemofiltration was performed were also divided into three subgroups after the distribution analysis which was done according to body surface area. "Mosteller's formula" was used to calculate the body surface area $\left(\operatorname{VYA}\left(\mathrm{m}^{2}\right)=([\right.$ Height $(\mathrm{cm}) \times$ Weight $(\mathrm{kg})] / 3600)^{1 / 2}$. A graphic was formed by calculating hemofiltration amount per square meter of 60 patients (Figure 1). Grouping was done regarding homogeneous distribution after graphic chart. Three subgroups were formed consisting of: Group A; 0 - $299 \mathrm{ml}$ of hemofiltration performed, Group B; 299 - $600 \mathrm{ml}$ of hemofiltration performed and Group C; $600 \mathrm{ml}$ and more hemofiltration performed. Weight, body surface area, the amount of hemofiltration, the surgical operation, duration of cardiopulmonary bypass, duration of cross clamp, ejection fraction (EF), sex, age, the amount of transfused blood, the amount of postoperative drainage and duration of stay at the postoperative intensive care unit, extubation time, length of hospital stay, preoperative and postoperative hematocrit values of the patients were all recorded.

Our indication in the hemofiltration performed group due to coronary artery disease was to provide hemoconcentration after the pump in the patient group who had excess hemodilution during cardiopulmonary bypass. In patients with 


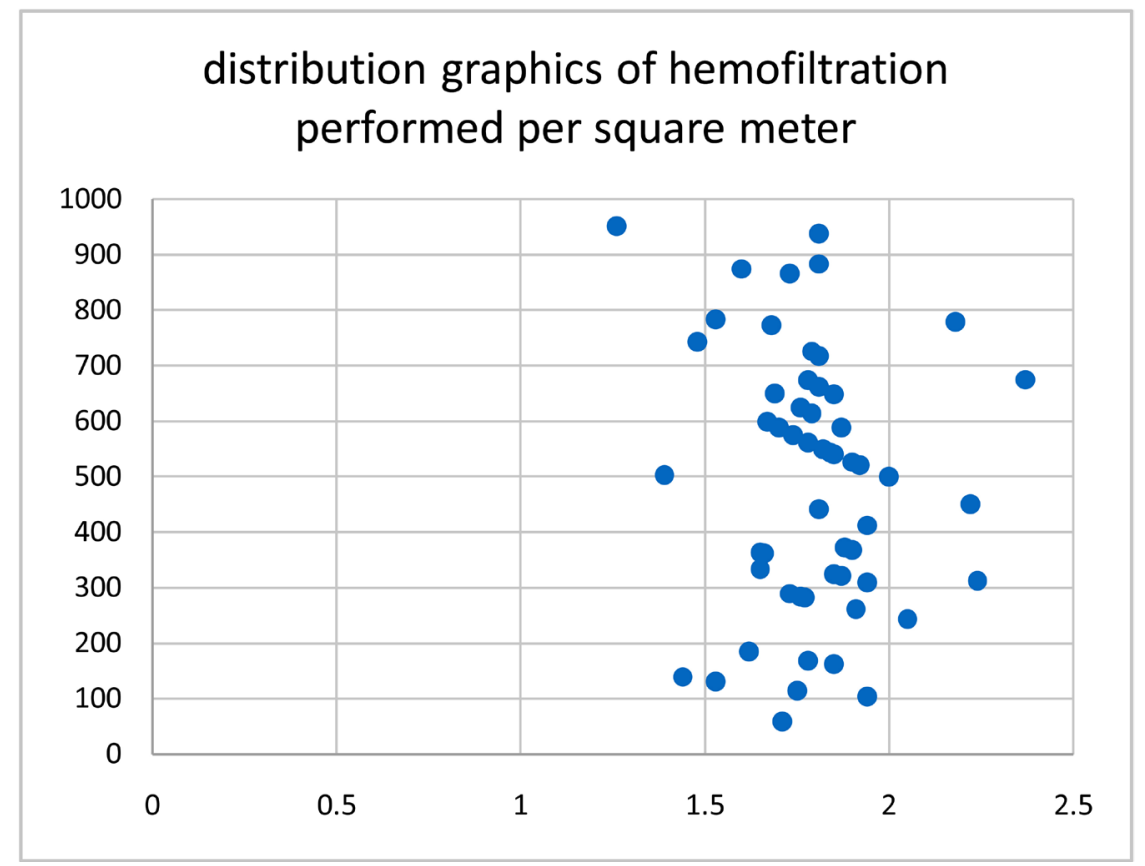

Figure 1. Graphics of hemofiltration performed per square meter. X-axis: Body surface area $\left(\mathrm{m}^{2}\right), \mathrm{Y}$-axis: hemofiltration amount $(\mathrm{ml})$ of per square meter.

hematocrit value below 20\% according to hematocrit follow-up during CPB, hemofiltration kit was added to cardiopulmonary bypass system and performed throughout the perfusion.

\section{Statistical Analysis}

All the analyses were done by using software packages of statistical analysis SPSS17.0. The consistency with normal distribution of the numerical variables was tested by the Kolmogorov Smirnov test. Categorical variables were described by using frequency and percentage; numerical variables were described by using mean and standard deviation, or median and minimum-maximum values. Relationship between categorical variables was investigated by Chi-square test and, the relationship between numerical variables was investigated by Spearman Correlation Analysis. Two independent median values were compared with the Mann Whitney $U$ test, and more than two independent median values were compared with the Kruskal Wallis test. Two independent means were compared with the Student $t$ test. Two dependent means were compared with the Dependent Sample $t$ test. The study was conducted at 95\% confidence level $(\mathrm{p}<0.05$ was accepted as statistically significant).

\section{Findings}

Demographic data and diagnostic features of patients are shown in (Table 1). There was not any statistically significant difference in the two groups regarding age, median height, median weight, ejection fraction, total perfusion time, median aortic cross clamp time, amount of drainage, need for inotropic support, 
Table 1. Demographic data and diagnostic features of patients.

\begin{tabular}{|c|c|c|c|c|}
\hline & TOTAL $(\mathrm{n}=226)$ & $\mathrm{HF}(+)(n=60)$ & HF $(-)(n=166)$ & $\mathrm{p}$ \\
\hline Age (Median, Min-Max) & $59(27-83)$ & $63.5(27-78)$ & $57(30-83)$ & $<0.001$ \\
\hline \multicolumn{5}{|l|}{$\operatorname{Sex}(n, \%)$} \\
\hline Males & $147(65 \%)$ & $35(58.3 \%)$ & $112(67.5 \%)$ & \multirow{2}{*}{0.203} \\
\hline Females & $79(35 \%)$ & $25(41.7 \%)$ & $54(32.5 \%)$ & \\
\hline Height $(\mathrm{cm})$ (Median, Min-Max) & $163(132-187)$ & $163(142-186)$ & $163(132-187)$ & 0.802 \\
\hline Weight (kg) (Median, Min-Max) & $72(40-130)$ & $71(40-130)$ & $72(40-101)$ & 0.614 \\
\hline Ejection fraction (\%) (Median, Min-Max) & $55(30-68)$ & $55(30-68)$ & $55(30-66)$ & 0.820 \\
\hline EuroSCORE I value (Median, Min-Max) & $3(0-11)$ & $5(0-11)$ & $3(0-11)$ & $<0.001$ \\
\hline $\begin{array}{l}\text { Degree of hypothermia }{ }^{\circ} \mathrm{C} \\
\quad(\text { Median, Min-Max) }\end{array}$ & $32(30-33)$ & $32(30-33)$ & $32(30-33)$ & 0.051 \\
\hline $\begin{array}{l}\text { Duration of aortic cross clamp (min) } \\
\text { (Median, Min-Max) }\end{array}$ & $66(19-343)$ & $65(27-120)$ & $66(19-343)$ & 0.997 \\
\hline Total perfusion time (min) $($ Mean \pm SS) & $98.5 \pm 29.5$ & $98.0 \pm 25.9$ & $98.7 \pm 30.8$ & 0.886 \\
\hline \multicolumn{5}{|l|}{ Need for Inotropics ( $\mathrm{n}, \%)$} \\
\hline Yes & $78(34.5 \%)$ & $32(53.3 \%)$ & $46(27.7 \%)$ & \multirow{2}{*}{$<0.001$} \\
\hline No & $148(65.5 \%)$ & $28(46.7 \%)$ & $120(72.3 \%)$ & \\
\hline Amount of drainage (cc) (Median, Min-Max) & $650(150-5000)$ & $650(250-1550)$ & $650(150-5000)$ & 0.310 \\
\hline Use of blood products (U) (Median, Min-Max) & $3(0-15)$ & $2(0-10)$ & $3(0-15)$ & 0.088 \\
\hline Extubation time (min) (Median, Min-Max) & $\begin{array}{c}240 \\
(70-1600)\end{array}$ & $\begin{array}{c}240 \\
(120-980)\end{array}$ & $\begin{array}{c}232.5 \\
(70-1600)\end{array}$ & 0.112 \\
\hline DSICU (day) (Median, Min-Max) & $2(1-36)$ & $2(1-8)$ & $2(1-36)$ & 0.044 \\
\hline DSH (day) (Median, Min-Max) & $8(2-45)$ & $8(2-17)$ & $8(5-45)$ & 0.454 \\
\hline Preop HTC $($ Mean \pm SS $)$ & $39.1 \pm 4.5$ & $36.9 \pm 4.4$ & $39.8 \pm 4.3$ & $<0.001$ \\
\hline Postop HTC (Mean \pm SS) & $30.7 \pm 2.8$ & $30.0 \pm 3.8$ & $30.9 \pm 2.4$ & 0.102 \\
\hline$\% \Delta \mathrm{HTC}$ (Median, Min-Max) & $21.7((-20)-50)$ & $16.9((-10)-40)$ & $22.5((-20)-50)$ & 0.006 \\
\hline \multicolumn{5}{|l|}{ Mortality (n,\%) } \\
\hline Discharge & $218(96.5 \%)$ & $56(93.3 \%)$ & $162(97.6 \%)$ & \multirow{2}{*}{0.213} \\
\hline Exitus & $8(3.5 \%)$ & $4(6.7 \%)$ & $4(2.4 \%)$ & \\
\hline
\end{tabular}

DSICU: Duration of stay in intensive care unit, DSH: Duration of stay in hospital, HF: Hemofiltration, HTC: Hematoctit, U: Unit.

need for blood products, duration of stay in hospital, extubation time, postoperative hematocrit values and mortality (Table 1).

EuroSCORE I value was higher in the patients whom hemofiltration was performed and statistically significant difference was found in two groups. More inotrop was needed in the hemofiltration group.

There was not any statistically significant difference in all three groups regarding age, sex, ejection fraction, EuroSCORE I values, degree of hypothermia, median aortic cross clamp time, amount of drainage, need for inotropic support, need for blood products, duration of stay in ICU, extubation time, preoperative 
and postoperative hematocrit values and mortality.

Total perfusion time was calculated in Group A as median 92 (40-131) mins, in Group B as median 94 (50-145) minutes and in Group C as median 115 (60-150) minutes. In Group $C$ the values of median total perfusion time were higher than the others and there was a statistically significant difference ( $\mathrm{p}=$ 0.025). Durations of stay in hospital were; median 7 (3-9) days in Group A, median 8 (2-17) days in Group B and median 8 (6-14) days in Group C. Statistically significant difference was found in median values durations of hospital stay of three groups $(\mathrm{p}=0.038)$ (Table 2$)$.

\section{Discussion}

Hemofiltration is useful for ensuring fluid hemoconcentration in the bypass cycle before the bypass is terminated. In this technique, filtration of the excess fluid of extracorporeal pump volume (combination of patient's blood and primal

Table 2. Comparison of hemofiltration performed per square meter.

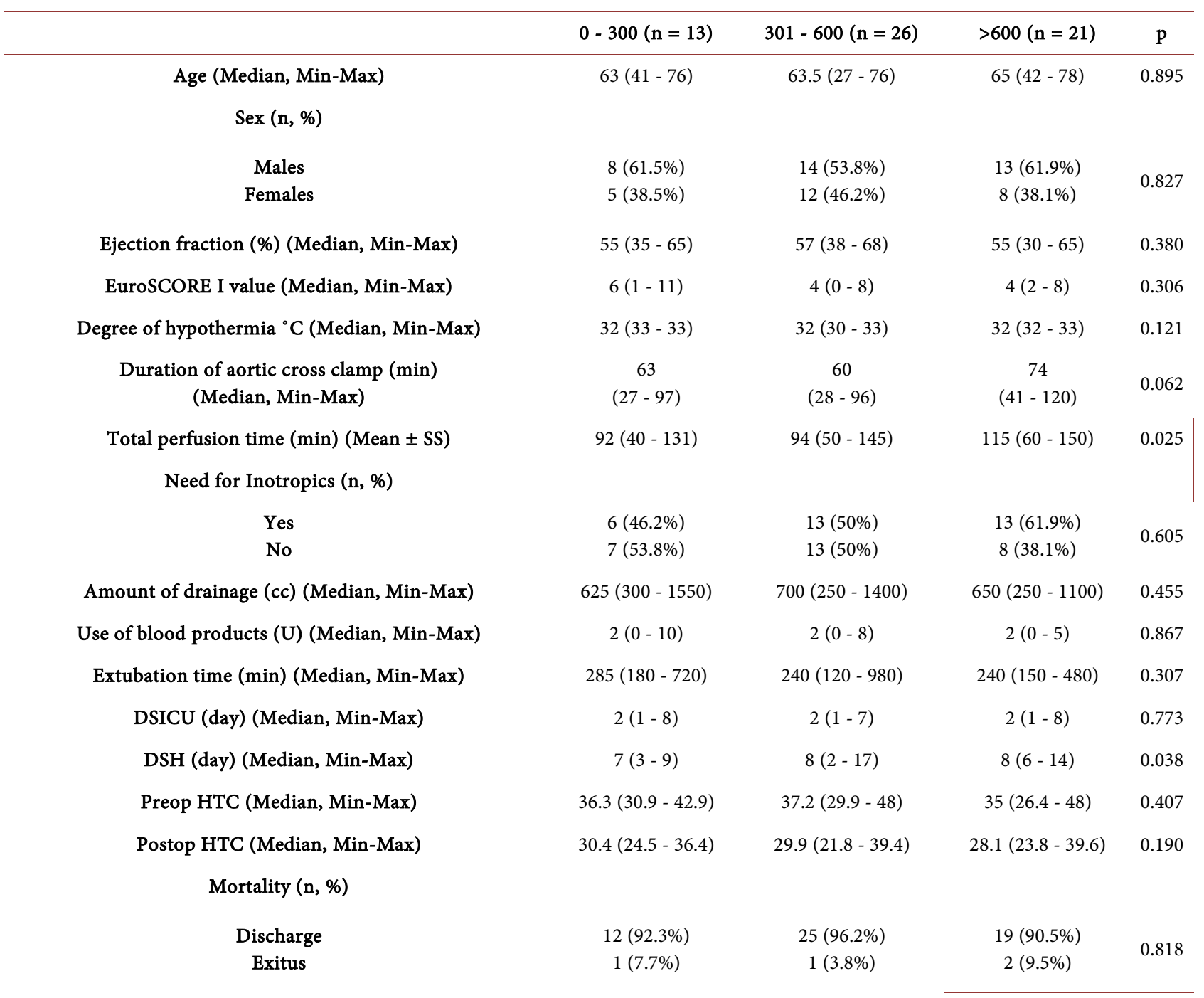

DSICU: Duration of stay in intensive care unit, DSH: Duration of stay in hospital, HTC: Hematocrit. 
pump fluid) which causes excessive hemodilution, is provided to remove it from the system.

Hematocrit values of the patients decrease during cardiopulmonary bypass. Hemodilution together with hypothermia at low perfusion pressures during $\mathrm{CPB}$, is a desired technique for organ perfusion and protection. In a study by Kizlttepe et al., 40 adult patients undergoing cardiac surgery were evaluated. Kizltepe and his colleagues separated the patients into 2 groups, they applied modified ultrafiltration with conventional ultrafiltration in one group and they did not apply ultrafiltration in the other group. They found that at the end of $\mathrm{CPB}$, hematocrit and hemoglobin levels decreased due to hemodilution but hemoglobin hematocrit levels increased significantly in ultrafiltration group [8] [9]. In their study involving 8 cases of adult cardiac surgery Fujita and colleagues carried out modified hemofiltration at the end of the $\mathrm{CPB}$, and reported that hematocrit and erythrocyte values were significantly increased after modified hemofiltration [10]. Sever and colleagues evaluated 27 patients who had open heart surgery in their study. They divided the patients into 2 groups, and in one group they only applied conventional ultrafiltration and in the other group they applied conventional ultrafiltration together with modified ultrafiltration. This team reported that the hematocrit levels were lower in both groups after CPB and that the hematocrit values were not significantly changed in the conventional ultrafiltration group whereas the hematocrit values were significantly increased in the modified ultrafiltration group [11].

In this study, we found a statistically significant difference between the groups with and without hemofiltration in terms of preoperative and postoperative hematocrit values. Since the amount of fluid withdrawn from the intravascular area provides hemoconcentration, the change between preoperative and postoperative hematocrit values was less in the hemofiltration group as expected. This is the inverse of the hemodilution paradigm used to lower hematocrit in CPB and is already a known physiological result. In the subgroups of the hemofiltration performed patients, there was no statistically significant difference in terms of the blood transfusions in all three groups $(\mathrm{p}=0.867)$. According to the preoperative and postoperative hematocrit values, there was no statistically significant difference according to the amount of hemofiltration performed per square meter ( $\mathrm{p}=0.407, \mathrm{p}=0.190$ respectively).

After cardiac surgery drain tube isused to prevent decompression of the mediastinum in the postoperative period and the development of life-threatening cardiac tamponade [12]. Naveed D, Khan RA, et al. [13], published a prospective randomized controlled study in 2016 and compared 40 patients with modified ultrafiltration and 40 patients without ultrafiltration. They found that the amount of postoperative drainage was significantly less in the ultrafiltration group. In their study on hemofiltration during cardiopulmonary bypass surgery in patients undergoing open heart surgery at high risk, published in 2003, Raman JS and colleagues found less postoperative hemorrhage (drainage) in the 
hemofiltration group [14]. Günaydın S and Gourlay T have found a significant reduction in post-operative bleeding and transfusion need in their work with new generation ultrafiltration techniques in 2013 [15].

In our study, median drainage amount of 226 patients was $650 \mathrm{cc}$. In both groups, median values of the amount of drainage were determined to be $650 \mathrm{cc}$. There was no statistically significant difference in hemofiltration and non-hemofiltration groups. In subgroup analysis; In the group with 0-300 $\mathrm{ml}$ ultrafiltration per square meter the drainage was calculated fairly less as $625 \mathrm{cc}$, the drainage was $700 \mathrm{cc}$ in the $301-600 \mathrm{ml}$ ultrafiltration group and it was $650 \mathrm{cc}$ at more than $600 \mathrm{ml}$ ultrafiltration group. The differences were not statistically significant $(\mathrm{p}=0.455)$.

One of the important developments in cardiac anesthesia is the emergence of fast-track application as an alternative to high-dose opioid anesthesia, which has traditionally been used in open-heart surgery due to its superiority in hemodynamic stability [16] [17].

Due to the need for long-term mechanical ventilation support due to high-dose opioid use and consequently delayed extubation, delays recovery, prolongs intensive care and hospital stay. Thus, the cost of the operation increases and the circulation of patients in the clinic decrease. The "fast-track" protocol, which increases patient circulation in line with today's economic conditions and provides economic return by reducing intensive care and hospital stay, provides early extubation and mobilization without reducing patient comfort [18]. Early extubation is a key step in the "fast track" application. Early extubation is expressed as extubation in the first 5 hours after open heart surgery. The objective is a stabile patient with normal post-operative hemodynamics, spontaneous respiration has returned, and that can be extubated on demand [19]. In the study of Journois D. et al. [20] in 1996, they removed the ultrafiltration complement factors and found a decrease in the need for postoperative mechanical ventilation due to faster return to pulmonary function. Türkoz A et al. published a study in 2013 on hemodynamic parameters and pulmonary functions, and showed that pulmonary compliance increased and blood gas parameters improved rapidly in acute period in ultrafiltration group. However, there was no significant difference in the time to extubation and in the duration of intensive care stay [21].

In our study, the time from the patient's separation from the mechanical ventilator did not differ between the hemofiltration group and the non-hemofiltration group. There was no significant difference between extubation durations in subgroup analysis $(\mathrm{p}=0.307)$.

In a randomized pilot study published in 2013, the effects of hemofiltration during CBP on hospital cost were investigated. In this study, the time to extubation and the length of intensive care unit stay were taken as criteria and the value of mortality was considered important [22]. In hemofiltration group, intensive care unit stay was found to be less than control groups. The study of Zhang $\mathrm{T}$ and his colleagues draw attention because the number of their patients is higher than other studies [23]. They found the intensive care unit stay lesser in the ul- 
trafiltration group during CBP. However, they do not recommend the routine application of hemofiltration during CBP, but tell that it should be compared with other hemofiltration methods.

In our study, median intensive care unit stay was recorded as 2 days in all groups. It was found to be statistically significantly less in the hemofiltration performed group $(\mathrm{p}=0.044)$. In the subgroup analysis, 2 days of intensive care unit stay was determined in all 3 groups according to the amount of hemofiltration applied per square meter and this was not statistically significant $(\mathrm{p}=$ 0.773). From the point of view of the hospital stay; the groups with and without hemofiltration stayed at the hospital for 8 days and this did not make statistical significance. In the subgroup analysis, $0-300 \mathrm{ml}$ per square meter hemofiltration group remained less in the hospital (7 days) than in the other groups (8 days), which was statistically significant. In this group, the duration of aortic cross and the duration of total perfusion were also found to be lesser. The shortage of hospital stay may be due to the fact that the comorbidity factors of the patients are less and the surgical procedures they are experiencing are less complicated.

When the hemofiltration during $\mathrm{CPB}$ and non-hemofiltration groups were assessed in terms of mortality, there was no statistically significant difference in the mortality rate though it is higher in the hemofiltration group. According to the EuroSCORE I scoring system made before the operation in terms of mortality, the high mortality prospect in the hemofiltration group was high and confirmed as expected after the operation. Therefore, it is not considered that hemofiltration is a factor affecting mortality in this group of patients, whose EuroSCORE I values are already high. Furthermore, when looking at the amount of hemofiltration-body surface area relationship, the amount of hemofiltration applied per square meter was not found to be a factor affecting the mortality when the hemofiltration subgroups were evaluated $(\mathrm{p}=0.818)$.

If we look at the groups according to the amount of hemofiltration made per square meter; in the A, B, and C groups with no difference in age, sex, ejection fraction, EuroSCORE I values, preoperative hematocrit levels, and hypothermia grades, there was no difference in the time to extubation, postoperative hematocrit, intensive care stay, blood product requirement, drainage volume and mortality. In group C, the duration of hospital stay was significantly higher.

\section{Conclusion}

As a result, no effect was observed on the mortality of the relationship between the amount of hemofiltration applied during CBP and body surface area. There is still need for a prospective study on this subject. Will there be a standard amount of hemofiltration to be applied according to the body surface area?

\section{Limitations of This Study}

The small patient population and its retrospective nature are the limitations of the study. 


\section{Conflicts of Interest}

The authors declare no conflicts of interest regarding the publication of this paper.

\section{References}

[1] Gielen, C.L., Brand, A., van Heerde, W.L., Stijnen, T., Klautz, R.J. and Eikenboom, J. (2016) Hemostatic Alterations during Coronary Artery Bypass Grafting. Thrombosis Research, 140, 140-146.

[2] Boodhwani, M., Hamilton, A., Varennes, B., Mesana, T., et al. (2010) A Multicenter Randomized Controlled Trial to Assess the Feasibility of Testing Modified Ultrafiltration as a Blood Conservation Technology in Cardiac Surgery. The Journal of Thoracic and Cardiovascular Surgery, 139, 701-706.

[3] Yokoyama, K., Takabayashi, S., Komada, T., Onoda, K., Mitani, Y. and Iwata (2009) Removal of Prostaglandin E2 and Increased Intraoperative Blood Pressure during Modified Ultrafiltration in Pediatric Cardiac Surgery. The Journal of Thoracic and Cardiovascular Surgery, 137, 730-735.

[4] Nicolas Blanchard, M.D., Yann Toque, M.D. and Faouzi Trojette, M.D. (2000) Hemodynamic and Echocardiographic Effects of Hemofiltration Performed during Cardiopulmonary Bypass. Journal of Cardiothoracic and Vascular Anesthesia, 14, 393-398. https://doi.org/10.1053/jcan.2000.7925

[5] Bando, K., Turrentine, M.W., Vijay, P., et al. (1998) Effect of Modified Ultrafiltration in High-Risk Patients Undergoing Operations for Congenital Heart Disease. The Annals of Thoracic Surgery, 66, 821-827.

[6] Kopman, E.A. and Ferguson, T.B. (1978) Pulmonary Edema Following Cardiopulmonary Bypass. Anesthesia \& Analgesia, 57, 367-370.

https://doi.org/10.1213/00000539-197805000-00017

[7] Patel, B., Jeroudi, M.O. and Bolli, R. (1990) Pathogenesis of İschemic Myocardial İnjury and Methods of Myocardial Protection. In: Garson Jr., A., Bricker, J.T. and McNamara, D.G., Eds., The Science and Practice of Pediatric Cardiology, Lea \& Febiger, Philadelphia, PA, 266-279.

[8] Coşkun, I., Çölkesen, Y., Demirtürk, O.S., et al. (2003) The Effects of Perioperative Ultrafiltration on Postoperative Outcomes in Dialysis-Dependent Patients Undergoing Open Heart Surgery. Turkish Journal of Thoracic and Cardiovascular Surgery, 21, 603-609.

[9] Kiziltepe, U., Uysalel, A., Corapcioglu, T., Dalva, K., Akan, H. and Akalin, H. (2001) Effects of Combined Conventional and Modified Ultrafiltration in Adult Patients. Annal of Thoracic Surgery, 684-693, 71. https://doi.org/10.1016/S0003-4975(00)02518-2

[10] Fujita, M., Ishihara, M., Kusama, Y., Shimizu, M., Kimura, T., Iizuka, Y., et al. (2004) Effect of Modified Ultrafiltration on İnflammatory Mediators, Coagulation Factors and Other Proteins in Blood after an Extracorporeal Circuit. Artificial Organs, 28, 310-313. https://doi.org/10.1111/j.1525-1594.2004.47230.x

[11] Sever, K., Tansel, T., Başaran, M., Kafali, E., Ugurlucan, M. and Ali Sayın, O. (2004) The Benefits of Continuous Ultrafiltration in Pediatric Cardiac Surgery. Scandinavian Cardiovascular Journal, 38, 307-311. https://doi.org/10.1080/14017430410021480

[12] Lancey, R.A., Gaca, C. and Vander, S.T.J. (2001) The Use of Smaller, More Flexible Chest Drains Following Open Heart Surgery. Chest, 119, 19-24.

https://doi.org/10.1378/chest.119.1.19

[13] McGiffin, D.C. and Kirklin, K. (1995) Cardiopulmonary Bypass for Cardiac Sur- 
gery. In: Sabiston Jr., D.C. and Spencer, F.C., Eds., Surgery the Chest, 61st Edition, WB Saundersm yol İI, Philadelphia, 1256-1271.

[14] Raman, J.S., Hata, M., Bellomo, R., Kohchi, K., Cheung, H.L. and Buxton, B.F. (2003) Hemofiltration during Cardiopulmonary Bypass for High Risk Adult Cardiac Surgery. The International Journal of Artificial Organs, 26, 753-757. https://doi.org/10.1177/039139880302600808

[15] Gunaydın, S. and Gourlay, T. (2013) Novel Ultrafiltration Technique for Blood Conservation in Cardiac Operations. Annal of Thoracic Surgery, 95, 2148-2151. https://doi.org/10.1016/j.athoracsur.2013.03.048

[16] Jai, H.L., Brenda, S., Jennifer, A., et al. (1999) Fast Track Recovery of Elderly Coronary Bypass Surgery Patients. Annal of Thoracic Surgery, 68, 437-441. https://doi.org/10.1016/S0003-4975(99)00510-X

[17] Cheng, D.H.C. (1998) Fast Track Cardiac Surgery Pathways. Anesthesiology, 88, 1429-1433. https://doi.org/10.1097/00000542-199806000-00002

[18] Silbert, B.S., Santamaria, J.D., et al. (1998) Early Extubation Following Coronary Artery Bypass Surgery: A Prospective Randomized Controlled Trial. Chest, 113, 1481-1488. https://doi.org/10.1378/chest.113.6.1481

[19] Hawkes, C.A., Dhileepan, S. and Foxcroft, D. (2003) Early Extubation for Adult Cardiac Surgical Patients. Cochrane Database of Systematic Reviews, No. 4.

[20] Journois, D., Israel-Biet, D., Pouard, P., et al. (1996) High-Volume, Zero-Balanced Hemofiltration to Reduce Delayed İnflammatory Response to Cardiopulmonary Bypass in Children. Anesthesiology, 85, 965-976. https://doi.org/10.1097/00000542-199611000-00003

[21] Türköz, A., et al. (2014) The Effect of Modified Ultrafiltration Duration on Pulmonary Functions and Hemodynamics in Newborns and İnfants Following Arterial Switch Operation. Pediatric Critical Care Medicine, 15, 600-607

[22] Matata, B., Mediratta, N., Morgan, M., Shirley, S. and Scawn, N. (2013) The Impact of Continuous Haemofiltration with High-Volume Fluid Exchange during Cardiopulmonary Bypass Surgery on the Recovery of Patients with Impaired Renal Function: A Pilot Randomised Trial. Health Technology Assessment, No. 17, 49.

[23] Zhang, T., Gao, C.-Q., Li, J.-C., Wang, J.-L., Li, L.-B. and Xiao, C.-S. (2009) Effect of Subzero-Balanced Ultrafiltration on Postoperative Outcome of Patients after Cardiopulmonary Bypass. Perfusion, 24, 401-408. https://doi.org/10.1177/0267659109357977 